\title{
Characteristics of Mother-Provider Interactions Surrounding Postpartum Return to Work
}

\author{
C. Randall Clinch, DO, MS, Joseph G. Grzywacz, PhD, Jenna Tucker, BA, \\ Jill K. Walls, MEd, and Thomas A. Arcury, PhD
}

Background: Many mothers with infants work full-time, yet little is known about communication between women and health care providers regarding returning to work (RTW).

Methods: Survey data were obtained from a community-based sample of mothers returning to fulltime employment within 4 months postpartum. Bivariate analyses ( $\chi^{2}$ and independent sample $t$ tests) and multivariate logistic regressions were specified.

Results: Eighty-three percent of mothers believed prenatal providers should discuss RTW, yet only $60 \%$ had such a discussion; $58 \%$ discussed RTW with their infants' provider. Black women (odds ratio, 2.6) and women in poverty (odds ratio, 3.6) more often reported having an RTW discussion with a prenatal provider whereas mothers with college degrees or higher (odds ratio, 2.7) more often had RTW discussions with their infant's provider. RTW discussions occurred $\leq 3$ times and were felt to be only somewhat useful. RTW discussions infrequently centered on maternal health (19.5\%) or infant health or development (35.5\%).

Conclusions: Women want providers to initiate RTW discussions. Providers should be aware that race, poverty status, and level of maternal education impact a mother's odds of having an RTW discussion. Additional research is required to further delineate the content of RTW discussions and to determine the clinical value of RTW discussions. (J Am Board Fam Med 2009;22:498-506.)

In an effort to enhance health outcomes, increased emphasis is being placed on health care providers' ability to provide patient-centered care. ${ }^{1-5} \mathrm{Al}-$ though various definitions of patient-centered care have been proposed, the fundamental idea is that the provision of patient-centered care depends on knowing the patient as a whole person in addition to providing accurate diagnosis and appropriate medical management. ${ }^{6-9}$ A patient-centered approach to care has been shown to improve health outcomes in the treatment of diabetes ${ }^{3}$ and muscu-

This article was externally peer reviewed.

Submitted 20 January 2009; revised 6 July 2009; accepted 7 July 2009.

From the Department of Family and Community Medicine, Wake Forest University School of Medicine, WinstonSalem, NC.

Funding: This research was supported by a grant from the Eunice Kennedy Shriver National Institute for Child Health and Human Development (R21 HD48601).

Prior presentation: Preliminary results from this paper were presented at the Conference on Families and Health of the Society of Teachers of Family Medicine, New Orleans, LA (February 29, 2008).

Conflict of interest: none declared.

Corresponding author: C. Randall Clinch, DO, MS, Department of Family and Community Medicine, Wake Forest University School of Medicine, Medical Center Boulevard, Winston-Salem, NC 27157-1084 (E-mail: crclinch@ wfubmc.edu). loskeletal conditions, ${ }^{4}$ in decreasing general complaints of discomfort and improving emotional health, ${ }^{5}$ and in improving patient satisfaction. ${ }^{2}$

The past 4 decades have seen significant increases in the number of women in the labor force. In $1970,43 \%$ of women 16 years or older were in the labor force compared with $59 \%$ in $2006 .{ }^{10}$ Women 16 years of age or older with a child younger than 3 years comprised $56 \%$ of the labor force in $2006 .{ }^{10}$ Two-thirds of women delivering their first child between the years 2001 to 2003 worked during their pregnancy; of those, $58 \%$ returned to work within 3 months. ${ }^{11}$ Despite these shifts in women's employment little is known about the interactions women have with their health care providers regarding their return to work (RTW) after the delivery of a child. Discussing RTW with pregnant or postpartum women fits into the patient-centered care framework because it provides an opportunity to understand a key aspect of women's lives outside of the biomedical condition of pregnancy.

It is widely accepted that women's employment is generally associated with more favorable health outcomes with respect to physical and psychological health ${ }^{12}$; nevertheless, conflicts that inevitably 
arise for working parents can undermine some of the health advantages gained by employment. In the general population, difficulty combining work and family has been associated with a greater risk of physical disorders such as hypertension ${ }^{13}$ and obesity, ${ }^{14}$ as well as elevated rates of psychiatric disorders. ${ }^{15}$ Specifically among postpartum women, difficulty combining work and family is associated with greater physical and emotional symptoms and lower self-rated health. ${ }^{16}$ Indeed, recognizing the potential public health value, the National Institutes of Health has established the Work, Family, Health, and Well-Being Initiative, through which research is being undertaken to identify solutions for minimizing work-family conflict as a comprehensive approach to improving population health. ${ }^{17}$

Despite the large number of pregnant and postpartum mothers in the labor force and the potential health-related concerns that may accompany RTW, examination of patient-provider communication about RTW has received scant attention. Whether women want providers to discuss issues about RTW and the current frequency and content of such discussions is unknown. The goal of this study was to provide an initial description of patient-provider communication surrounding women's postpartum RTW. To accomplish this goal we (1) described the demographic and personal characteristics of pregnant and postpartum women having a RTW discussion with a provider and (2) documented the frequency, maternal value, and content of RTW discussions between pregnant and postpartum women and providers.

\section{Methods}

The data for this study are from a communitybased sample of employed mothers of newborns in Forsyth County, NC. The study was designed to document the strategies that employed mothers used to balance their work and family lives and to determine whether variation in mothers' strategies for combining work and family contributed to differences in women's and infants' health. Data were collected at 4 points: at a baseline assessment, when infants were 4 months old and at follow-up assessments when children were 8,12 , and 16 months old. Measures of patient-provider communication were obtained during the baseline (4-month) assessment. One question related to the content of the RTW discussion was collected at both the 4-month and 8-month assessments. Institutional review board approval for this study was granted from both Wake Forest University Health Sciences Center and the Forsyth Medical Center.

\section{Sample Frame}

The sample frame constructed for this study consisted of new mothers working $\geq 30$ hours per week. All infants born in Forsyth County receive care through a single mother-infant hospital unit at some point during the first week of life. A member of the investigative team (CRC) monitored the daily census of the mother-infant unit and identified mothers who reported working during their pregnancy based on information contained in the electronic medical record. Women identified as being employed were approached in their hospital room after their infant was born, but before discharge, to introduce the study and identify whether the mother was willing to be contacted within the next 3 months about the study. A total of 704 mothers were approached and 630 (89\%) provided approval for subsequent contact.

All women in the sampling frame received a series of personal contacts plus nominal mailed gifts. Within 1 week of returning home from the hospital, women entering the sample frame were mailed a personalized "congratulations" card from the investigative team. When the newborn was 1,2 , and 3 months old mothers received age-specific educational materials about their child's development as well as how to evaluate and respond to common illnesses among infants (eg, ear infection, fever). These mailings served 2 purposes. First, like the basic strategy outlined by Dillman ${ }^{18}$ for promoting good responses to mailed surveys, the mailings were intended to build a sense of personal relationship with and social obligation to the project. Second, the mailings were intended as tracking devices: if mailings were returned, it signaled a need for an alternate strategy for contacting mothers. If a letter was returned, the address was either corrected using the information on the returned mail (ie, a forwarding address) or the mother was contacted by phone to correct the address.

\section{Recruitment}

Five hundred eighteen of the 630 mothers granting approval to be contacted were randomly selected 


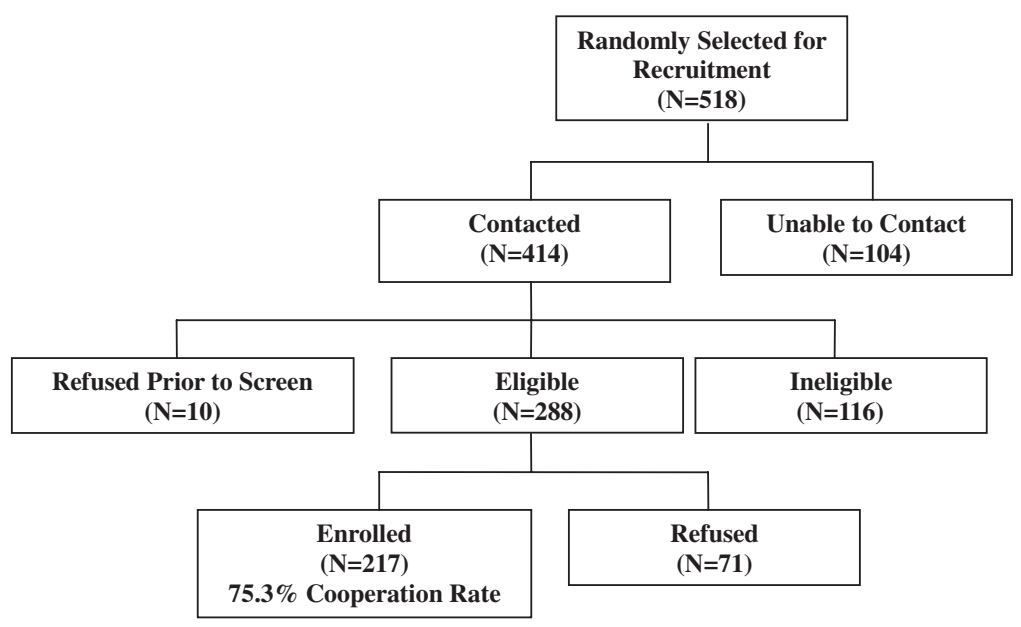

Figure 1. Flow of study participants.

for contact and potential recruitment. Eligible study patients were postpartum women (age 18 and older) who (1) had already returned or planned to return to full-time work ( $\geq 30$ hours per week) outside the home by the time their children were 4 months old, and (2) had infants younger than 4 months. Exclusion criteria included having a child with special health care needs or a mother who did not speak English adequately enough to participate in the interview. Recruitment success is illustrated in Figure 1. Of the 288 eligible mothers, 217 agreed to participate and completed a baseline interview, which yielded an overall cooperation rate of $75.3 \%$. Among the 116 mothers ineligible for the study, 94\% were ineligible because they did not meet the employment-related inclusion criterion.

\section{Data Collection}

Data were obtained from interviewer-administered survey questionnaires. A team of 6 trained interviewers collected all data during face-to-face interviews. Interviewers participated in an 8-hour training program consisting of a thorough review of the study purpose, participant selection and recruitment, data collection procedures, and tips for recognizing participant fatigue and potential child abuse or neglect. More than $10 \%$ of participants were randomly selected and contacted for purposes of quality control. Project staff called participants to verify key data elements from completed interviews and whether the participant received the incentive for the interview. In all cases, interviewers were reported to be courteous and professional, all participants received their incentives, and there was no evidence that interviewers falsified data.

\section{Measures}

Individual Demographic Characteristics

Variables included maternal age, ethnicity (black versus non-Hispanic white), and marital status (currently married vs single). Maternal level of education categories were defined as " $<$ college graduate" (which included high school graduate [including equivalency] or less, some college, or associate's degree); or "college degree or higher" (which included bachelor's, graduate, or professional degree). Annual household income was categorized based on sample quartiles. Income was also categorized as above or below the 2007 poverty thresholds.

\section{Individual Personal Characteristics}

Variables included the type of childcare arrangement (family member, formal day care, other); infant feeding method (strictly breastfeeding or not); perceived socioeconomic status, ${ }^{19}$ length of maternity leave from work; and economic hardship. Economic hardship was assessed by first computing the sum of 2 variables-one that assessed if the mother was having difficulty paying bills and one that assessed the mother's monthly financial status-then dichotomized the result using a split at the median into "less hardship" and "more hardship."

\section{Employment Characteristics}

Hours worked were assessed in terms of the total number of hours per week worked on all jobs since the mother returned to work. 


\section{Maternal-Provider Communication Characteristics}

The literature is devoid of existing items or instruments assessing patient-provider communication among mothers returning to work after the birth of a child. As such, we included questions to identify if mothers were having RTW discussions with their prenatal care provider or their infant's health care provider, the frequency of such discussions, who initiated such discussions, the degree of usefulness mothers placed on such discussions, and if mothers felt providers should have discussions regarding RTW. Questions about the content of RTW discussions asked whether the discussion focused primarily on maternal physical health, maternal mental health, child physical health, child development, or "other." Questions regarding the content of RTW discussions were refined and implemented after baseline interviews were begun. As such, $48.4 \%$ of mothers were asked questions about the content of the RTW discussions at the 4-month baseline interview whereas $51.6 \%$ of mothers were asked at the 8 -month follow-up interview.

\section{Analyses}

Bivariate differences were tested using statistics appropriate for metric and type of variable. Differences in proportions between characteristics of women in our sample versus women in the county were tested using $Z$ tests for differences in 2 proportions. $\chi^{2}$ tests were used to test associations between 2 categorical variables, such as having had an RTW discussion with a health care provider and maternal education level. Mean comparisons were tested using independent samples $t$ tests. A backwards stepwise model building procedure with likelihood ratio statistics was used to arrive at the most parsimonious logistic regression model for our outcomes of interest (ie, having an RTW discussion or not with the mother's prenatal care provider; having an RTW discussion or not with the infant's health care provider). All variables with $P<.20$ in bivariate analyses were advanced to multivariate analysis. ${ }^{20}$ All analyses were conducted using SPSS software version 16.0.2 (SPSS Inc., Chicago, IL).

\section{Results}

A comparison of the mothers in our study versus women in the same county ${ }^{21}$ is presented in Table 1. The mean age of the mothers in our study was 30.3 years (SD, 5.6 years). By design, the racial
Table 1. Comparison of Study Sample Versus County

Data

\begin{tabular}{lll}
\hline Variable & $\begin{array}{c}\text { Our } \\
\text { Sample }\end{array}$ & $\begin{array}{c}\text { County } \\
\text { Data* }^{*}\end{array}$ \\
\hline $\begin{array}{l}\text { Maternal age (years [SD]) } \\
\text { Ethnicity (\% [n]) }\end{array}$ & $30.3(5.6)$ & 37.4 \\
$\quad$ Black & $30.0(65)$ & $32.8(24,678)$ \\
$\quad$ Non-Hispanic white & $70.0(152)$ & $67.2(50,458)$ \\
Maternal education (\% [n]) & & \\
$\quad<$ College degree & $53.0(115)$ & $78.0(3,611)^{\dagger}$ \\
$\quad \geq$ College degree & $47.0(102)$ & $22.0(1,039)^{\dagger}$ \\
Married (\% [n]) & $77.0(167)$ & $60.7(2,824)^{\dagger}$ \\
Work (hours/week [SD]) & $39.6(5.5)$ & $50.3^{\ddagger}$ \\
\hline
\end{tabular}

*US 2000 Census; Women 15 to 50 years of age who had a birth during the past 12 months, Forsyth County, NC. ${ }^{21}$

${ }^{\dagger}$ Proportions differ based on results of a $\mathrm{Z}$ test for difference in 2 proportions with a $95 \%$ confidence value.

${ }^{\ddagger}$ Percentage of mothers who worked $\geq 35$ hours per week.

distribution was well matched to the county distribution, with $30 \%$ black and $70 \%$ non-Hispanic white mothers. County-level proportions presented reflect those of women aged 15 to 50 years who had given birth during the past 12 months in Forsyth County, NC. ${ }^{21}$ In comparison, our study participants were more highly educated than the general population of recent mothers, with $47 \%$ having a college degree or higher versus $22 \%$ of women in the county. More women in our study were married compared with women in the county $(77 \%$ vs $61 \%$, respectively). By design, women in our study were employed full-time, working, on average, 39.5 hours/week.

The majority of women in our study reported receiving their prenatal care from an obstetrician $(91.2 \%)$. The remainder of the care was provided by family physicians (5.1\%), midwives (1.4\%), nurse practitioners $(0.9 \%)$, or "other" $(0.9 \%)$.

Approximately $60 \%$ of study participants reported having had an RTW discussion with their prenatal health care providers (Table 2). In bivariate analyses, such discussions were more common among black mothers $(P=.003)$, mothers below the poverty threshold $(P=.01)$, and single mothers $(P=.02)$. Compared with mothers using family members or formal day care arrangements, fewer mothers using "other" childcare arrangements had an RTW discussion with their prenatal care providers $(P=.05$; Table 2$)$. "Other" childcare arrangement typically involved relying on informal babysitters or multiple childcare arrangements. 
Table 2. Characteristics Differentiating Working Mothers Having a Return to Work (RTW) Discussion with Their Prenatal Healthcare Provider

\begin{tabular}{|c|c|c|c|}
\hline & \multicolumn{2}{|c|}{$\begin{array}{l}\text { RTW Discussion with } \\
\text { Prenatal Provider }\end{array}$} & \multirow[b]{2}{*}{$P$} \\
\hline & Yes & No & \\
\hline \multicolumn{4}{|l|}{ Demographics } \\
\hline Age, years (n [mean]) & $131(30.2)$ & $85(30.6)$ & $.74^{*}$ \\
\hline Ethnicity & & & $.003^{\dagger}$ \\
\hline Black & $49(76.6)$ & $15(23.4)$ & \\
\hline Non-Hispanic white & $82(53.9)$ & $70(46.1)$ & \\
\hline Maternal education & & & $.97^{\dagger}$ \\
\hline $\begin{array}{l}\text { Less than college } \\
\text { degree }\end{array}$ & $69(60.5)$ & $45(39.5)$ & \\
\hline $\begin{array}{l}\text { College degree or } \\
\text { higher }\end{array}$ & $62(60.8)$ & $40(39.2)$ & \\
\hline Marital status & & & $.02^{\dagger}$ \\
\hline Currently married & $94(56.3)$ & $73(43.7)$ & \\
\hline Single & $37(75.5)$ & $12(24.5)$ & \\
\hline Household income & & & $.79^{\dagger}$ \\
\hline Bottom quartile & $31(67.4)$ & $15(32.6)$ & \\
\hline 2nd quartile & $32(64.0)$ & $18(36.0)$ & \\
\hline 3rd quartile & $29(59.2)$ & $20(40.8)$ & \\
\hline Top quartile & $30(58.8)$ & $21(41.2)$ & \\
\hline Poverty status & & & $.01^{\dagger}$ \\
\hline Below poverty & $18(85.7)$ & $3(14.3)$ & \\
\hline Above poverty & $113(57.9)$ & $82(42.1)$ & \\
\hline \multicolumn{4}{|l|}{ Personal characteristics } \\
\hline Type of childcare & & & $.05^{\dagger}$ \\
\hline Family member & $61(63.5)$ & $35(36.5)$ & \\
\hline Formal daycare & $63(63.0)$ & $37(37.0)$ & \\
\hline Other & $7(35.0)$ & $13(65.0)$ & \\
\hline Breastfeeding only & & & $.62^{+}$ \\
\hline Yes & $27(64.3)$ & $15(35.7)$ & \\
\hline No & $104(60.1)$ & $69(39.9)$ & \\
\hline Perceived SES & & & $.52^{\dagger}$ \\
\hline Low & $65(58.6)$ & $46(41.4)$ & \\
\hline High & $66(62.9)$ & $39(37.1)$ & \\
\hline Economic Hardship & & & $.89^{\dagger}$ \\
\hline Less hardship & $66(60.0)$ & $44(40.0)$ & \\
\hline More hardship & $64(61.0)$ & $41(39.0)$ & \\
\hline
\end{tabular}

All values provided as $\mathrm{n}(\%)$ unless otherwise indicated.

*Independent samples $t$ test.

${ }^{\dagger} \chi^{2}$ test.

SES, socioeconomic status.

The average length of maternity leave did not differ between those who had versus those who did not have an RTW discussion with a prenatal care provider (62.0 vs 65.2 days, respectively; $P=.28$ ). Results from a multivariate logistic regression model indicated that black mothers (odds ratio, 2.6; $P=.006)$ and those meeting the 2007 poverty threshold (odds ratio, 3.6; $P=.047$ ) were more likely than non-Hispanic white mothers and those above the poverty threshold, respectively, to have an RTW discussion with their prenatal care provider. Marital status and childcare arrangements were no longer significant in multivariate analysis.

More than one-half $(57.6 \%)$ of study participants reported having an RTW discussion with their infants' health care provider. Mothers with a college degree or higher $(P<.0001)$ and those among the highest income quartiles $(P=.05)$ more often reported having an RTW discussion with their infants' health care providers (Table 3). Mothers who had an RTW discussion with their infant's health care provider reported having a longer maternity leave than those who did not have an RTW discussion with their infant's health care provider (66.0 vs 59.4 days; $P=.03$ ). Trend-level evidence $(P<.10)$ suggested that mothers who exclusively breastfed and those above the 2007 poverty threshold were also more likely to report having an RTW discussion with their infant's health care provider. Maternal education was the only variable that survived multivariate analysis; the odds of having a RTW discussion with the infant's health care provider was greater only mothers with a college degree or higher (odds ratio, 2.7; $P=$ .001 ) in contrast to those with less than a college degree.

The majority of mothers $(83.4 \% ; 181$ of 217$)$, believed that prenatal care providers should discuss returning to work with pregnant women (Table 4). Among those having an RTW discussion with their prenatal care providers, such conversations were typically $(61 \%)$ initiated by the women, not the health care providers. The frequencies of such discussions were as follows: $41.2 \%$ had a single discussion, $48.1 \%$ had 2 to 3 discussions, and $10.7 \%$ had more than 3 discussions; similar data were not collected about discussions with the infants' health care providers.

The majority of women having an RTW discussion with their prenatal providers felt the discussion was somewhat useful (39.7\%), whereas $24.4 \%$ felt it was very useful and $35.9 \%$ felt the discussion was not useful at all. Similarly, the majority of women having an RTW discussion with their infants' health care providers felt the discussion was somewhat useful (49.2\%) whereas $29 \%$ felt the discussion was very useful and $21.8 \%$ felt the discussion was not useful at all (Table 4). 
Table 3. Characteristics Differentiating Working Mothers Having a Return to Work (RTW) Discussion with Their Infant's Healthcare Provider

\begin{tabular}{|c|c|c|c|}
\hline & \multicolumn{2}{|c|}{$\begin{array}{l}\text { RTW Discussion with } \\
\text { Infant's Healthcare } \\
\text { Provider }\end{array}$} & \multirow[b]{2}{*}{$P$} \\
\hline & Yes & No & \\
\hline \multicolumn{4}{|l|}{ Demographics } \\
\hline Age, years (n [mean]) & $125(30.1)$ & $92(30.5)$ & $.32^{*}$ \\
\hline Ethnicity & & & $.46^{\dagger}$ \\
\hline Black & $35(53.8)$ & $30(46.2)$ & \\
\hline Non-Hispanic white & $90(59.2)$ & $62(40.8)$ & \\
\hline Maternal education & & & $.001^{\dagger}$ \\
\hline Less than college degree & $53(42.4)$ & $62(67.4)$ & \\
\hline College degree or higher & $72(57.6)$ & $30(32.6)$ & \\
\hline Marital status & & & $.22^{+}$ \\
\hline Currently married & $100(59.9)$ & $67(40.1)$ & \\
\hline Single & $25(50.0)$ & $25(50.0)$ & \\
\hline Household income & & & $.05^{\dagger}$ \\
\hline Bottom quartile & $23(48.9)$ & $24(51.1)$ & \\
\hline 2nd quartile & $24(48.0)$ & $26(52.0)$ & \\
\hline 3rd quartile & $34(69.4)$ & $15(30.6)$ & \\
\hline Top quartile & $34(66.7)$ & $17(33.3)$ & \\
\hline Poverty status & & & $.06^{\dagger}$ \\
\hline Below poverty & $8(38.1)$ & $13(61.9)$ & \\
\hline Above poverty & $117(59.7)$ & $79(40.3)$ & \\
\hline \multicolumn{4}{|l|}{ Personal characteristics } \\
\hline Type of childcare & & & $.45^{\dagger}$ \\
\hline Family member & $53(54.6)$ & $44(45.4)$ & \\
\hline Formal daycare & $62(62.0)$ & $38(38.0)$ & \\
\hline Other & $10(50.0)$ & $10(50.0)$ & \\
\hline Breastfeeding only & & & $.09^{\dagger}$ \\
\hline Yes & $29(69.0)$ & $13(31.0)$ & \\
\hline No & $95(54.6)$ & $79(45.4)$ & \\
\hline Perceived SES & & & $.21^{\dagger}$ \\
\hline Low & $60(53.6)$ & $52(46.4)$ & \\
\hline High & $65(61.9)$ & $40(38.1)$ & \\
\hline Economic Hardship & & & $.23^{+}$ \\
\hline Less hardship & $68(61.8)$ & $42(38.2)$ & \\
\hline More hardship & $57(53.8)$ & $49(46.2)$ & \\
\hline
\end{tabular}

All values provided as $\mathrm{n}(\%)$ unless otherwise indicated.

*Independent samples $t$ test.

${ }^{\dagger} \chi^{2}$ test.

SES, socioeconomic status.

There was substantial variation in the content of women's RTW discussions with health care providers (Table 4). The content of nearly half (46.3\%) of the RTW discussions with prenatal health care providers focused on neither maternal health and well-being nor infant health or development. Indeed, only $19.5 \%$ of mothers had an RTW discussion focused on maternal health (ie, physical or mental); $10.6 \%$ discussed their infants' health or development whereas $23.6 \%$ discussed both of these topics. The content of RTW discussions with the infant's health care provider was more focused. Fully one-third (33.6\%) reported that the RTW discussion with their infants' health care providers centered on infant health or development, whereas $8.4 \%$ of mothers had a discussion about maternal health (ie, physical or mental), and $22.7 \%$ reported discussing both issues relevant to maternal and child health. Slightly more than onethird of RTW discussions (35.3\%) with infants' health care providers covered neither maternal nor child health.

\section{Discussion}

Surprisingly little is known about the patient-provider communication that may occur between a woman and her prenatal care provider or her infant's provider on the subject of returning to fulltime employment after the delivery of a child. Despite substantial growth since the 1970s in the percentage of mothers in the labor force, particularly mothers of infants, ${ }^{11}$ no publications exist addressing this specific patient-provider communication issue. Nichols and Roux ${ }^{22}$ suggest that women may not perceive health care providers as a source of support or information with respect to their postpartum RTW; however, mothers in their study were not specifically queried about communicating with their providers regarding RTW issues. Although they must be viewed as preliminary given the small sample, the results of our study contribute in several distinct ways to understanding communication patterns regarding women returning to work after the birth of a child.

The results of this study reveal that health care providers are missing an opportunity to practice patient-centered care; $83.4 \%$ of mothers in our sample thought prenatal care providers should talk about RTW as a part of routine prenatal care but only $60 \%$ of mothers had these conversations. Such discussions were, overall, infrequent, with the majority of mothers reporting 1 to 3 RTW discussions with their prenatal providers. This suggests that health care providers can enhance their patientcenteredness by initiating RTW discussions with employed women receiving prenatal care. Among those having RTW discussions, most conversations did not center on maternal or child health (ie, 


\begin{tabular}{|c|c|c|}
\hline & $\begin{array}{l}\text { RTW Discussion with } \\
\text { Prenatal Care Provider } \\
\qquad(\mathrm{n}=131)\end{array}$ & $\begin{array}{l}\text { RTW Discussion with } \\
\text { Infant's Healthcare Provider } \\
(\mathrm{n}=125)\end{array}$ \\
\hline \multicolumn{3}{|c|}{ Should prenatal provider discuss RTW?* } \\
\hline Yes & $119(65.7)$ & $\mathrm{n} / \mathrm{a}$ \\
\hline No & $11(32.4)$ & $\mathrm{n} / \mathrm{a}$ \\
\hline \multicolumn{3}{|l|}{ Mother initiated RTW discussion } \\
\hline Yes & $80(61.1)$ & $\mathrm{n} / \mathrm{a}$ \\
\hline No & $51(38.9)$ & $\mathrm{n} / \mathrm{a}$ \\
\hline \multicolumn{3}{|l|}{ Usefulness of RTW discussion: } \\
\hline Very useful & $32(24.4)$ & $36(29.0)$ \\
\hline Somewhat useful & $52(39.7)$ & $61(49.2)$ \\
\hline Not at all useful & $47(35.9)$ & $27(21.8)$ \\
\hline \multicolumn{3}{|l|}{ Content of RTW discussions ${ }^{* \dagger}$} \\
\hline Maternal health or well-being & $24(19.5)$ & $10(8.4)$ \\
\hline Infant health or development & $13(10.6)$ & $40(33.6)$ \\
\hline Both & $29(23.6)$ & $27(22.7)$ \\
\hline Other & $57(46.3)$ & $42(35.3)$ \\
\hline \multicolumn{3}{|l|}{ Frequency of RTW discussions } \\
\hline Once & $54(41.2)$ & $\mathrm{n} / \mathrm{a}$ \\
\hline 2 to 3 times & $63(48.1)$ & $\mathrm{n} / \mathrm{a}$ \\
\hline$>3$ times & $14(10.7)$ & $\mathrm{n} / \mathrm{a}$ \\
\hline
\end{tabular}

Data provide as $\mathrm{n}(\%)$.

*Column may not total due to missing data.

${ }^{\dagger}$ Data for this question only was collected at 4 months and 8 months.

RTW, return to work.

"other" was the most frequent content category) and a large proportion found little meaning in the discussions they had. Further research on the content of RTW discussions is necessary to understand the limited meaning mothers placed on RTW discussions. If such discussions centered on more perfunctory tasks (eg, obtaining maternity leave paperwork), limited meaning might be anticipated. Based on the broader patient-centered communication literature, ${ }^{1,5,6,23-25}$ more meaningful RTW discussions may lead to greater patient satisfaction, potentially better medical management of common health conditions (eg, diabetes, musculoskeletal conditions), and possibly better maternal and infant health outcomes.

An interesting pattern emerged among the women reporting RTW discussions with prenatal versus infant health care providers. Results from a multivariate logistic regression model indicated that the odds of having an RTW discussion with a prenatal health care provider were 2.6 times greater for black than for non-Hispanic white women and 3.6 times greater for women below the poverty threshold than for comparable women living above the poverty level. By con- trast, women who could be considered more advantaged (ie, those with a college degree or higher) were 2.7 times more likely to have an RTW discussion with their infant's health care providers compared with those with less education. This suggests that relatively disadvantaged women are more likely to have RTW discussions with their prenatal care provider whereas more advantaged women are more likely to have them with their infant's health care provider. Because only a small proportion of these discussions focused on maternal health and well-being or infant health and development, further research is required to identify the content of the majority of the RTW discussions. In addition, further study is necessary to determine why more than $40 \%$ of mothers found such discussions with either their prenatal providers or their infants' providers to be only somewhat useful.

The results of this study make important contributions to the literature; nevertheless, they need to be interpreted in light of their limitations. Although our sample is representative of working mothers in Forsyth County, NC, a racially and ethnically diverse metropolitan area, the results of 
our study may not generalize to other areas. The majority of mothers in our study received their prenatal care from obstetricians; therefore, results may not generalize to mothers receiving their care from family physicians or midwives. We did not collect data specifically about parity or the number of children to which a woman has given birth. Parity may affect a woman's perceived need to initiate an RTW discussion with her provider. Although we chose to collect data on the number of children cared for in the home under the presumption that the number of dependent children was of primary importance, future research should include both variables. In addition, our data are based on maternal self-report, which, despite being a practical method to have used in the current study, is limited in its ability to capture details about communication when compared with audio- or videotaping clinical encounters. Future studies should rely on more sophisticated measures of patientprovider communication collected in a prospective fashion.

\section{Conclusion}

Women want health care providers to discuss their RTW. At present, most mothers initiate such discussions and feel that they are only somewhat useful. Providers could enhance their patient-centeredness by initiating RTW discussions, but they should be aware that race, poverty status, and level of maternal education impact a mother's odds of having an RTW discussion. The task for future scholarship is to develop a more complete understanding of the content and related usefulness of RTW discussions and how such communication impacts maternal and infant health.

\section{References}

1. Robinson JH, Callister LC, Berry JA, Dearing KA. Patient-centered care and adherence: definitions and applications to improve outcomes. J Am Acad Nurse Pract 2008;20:600-7.

2. Kidd J, Marteau TM, Robinson S, Ukoumunne OC, Tydeman C. Promoting patient participation in consultations: a randomised controlled trial to evaluate the effectiveness of three patient-focused interventions. Patient Educ Couns 2004;52:107-12.

3. van Dam HA, van der Horst F, van den Borne B, Ryckman R, Crebolder H. Provider-patient interaction in diabetes care: effects on patient self-care and outcomes: a systematic review. Patient Educ Couns 2003;51:17-28.
4. Alamo MM, Moral RR, Perula de Torres LA. Evaluation of a patient-centered approach in generalized musculoskeletal chronic pain/fibromyalgia patients in primary care. Patient Educ Couns 2002;48:23-31.

5. Stewart M, Brown B, Donner A, et al. The impact of patient-centered care on outcomes. J Fam Pract 2000;49:796-804.

6. Epstein RM. The science of patient-centered care. J Fam Pract 2000;49:805-7.

7. Makoul G. Essential elements of communication in medical encounters: The Kalamazoo Consensus Statement. Acad Med 2001;76:390-3.

8. Smith RC, Marshall-Dorsey AA, Osborn GG, et al. Evidence-based guidelines for teaching patient-centered interviewing. Patient Educ Couns 2000;39:2736.

9. Sullivan M. The new subjective medicine: taking the patient's point of view on health care and health. Soc Sci Med 2003;56:1595-604.

10. Chao EL, Rones PL. Women in the labor force: a databook. Washington, DC: US Department of Labor, US Bureau of Labor Statistics; 2007.

11. Johnson TD. Maternity leave and employment patterns: 2001-2003. Current Population Report. Washington, DC: US Census Bureau; 2007.

12. Klumb PL, Lampert T. Women, work, and wellbeing, 1950-2000: a review and methodological critique. Soc Sci Med 2004;58:1007-24.

13. Frone MR, Russell M, Cooper ML. Relation of work-family conflict to health outcomes: a four-year longitudinal study of employed parents. J Occup Organ Psychol 1997;70:325-35.

14. Grzywacz JG. Work-family spillover and health during midlife: Is managing conflict everything? Am J Health Promot 2000;14:236-43.

15. Grzywacz JG, Bass B. Work, family, and mental health: testing different models of work-family fit. J Marriage Fam 2003;65:248-62.

16. Killien MG, Habermann B, Jarrett M. Influence of employment characteristics on postpartum mothers' health. Women Health 2001;33(1-2):63-81.

17. National Institutes of Health, Eunice Kennedy Shriver National Institute of Child Health and Human Development. Work, Family, Health, and Well-Being initiative. (2006). Available at: http:// www.nichd.nih.gov/research/supported/workhealthinit.cfm. Accessed April 21, 2009.

18. Dillman DA. Mail and internet surveys: the tailored design method. New York: Wiley; 2000.

19. Adler NE, Epel ES, Castellazzo G, Ickovics JR. Relationship of subjective and objective social status with psychological and physiological functioning: preliminary data in healthy white women. Health Psychol 2000;19:586-92.

20. Hosmer DW, Lemeshow S. Applied logistic regression. New York: John Wiley \& Sons; 1989.

21. US Census Bureau. American FactFinder. Available at: 
http://factfinder.census.gov/servlet/CTGeoSearchByListServlet?ds_name $=$ ACS_2007_3YR_G00_\&_ lang $=$ en\&_ts $=249831602697$. Accessed April 12, 2008.

22. Nichols MR, Roux GM. Maternal perspectives on postpartum return to the workplace. JOGN Nurs 2004;33:463-71.

23. Kinmonth AL, Woodcock A, Griffin S, Spiegal N, Campbell MJ. Randomised controlled trial of patient centred care of diabetes in general practice: impact on current wellbeing and future disease risk. BMJ 1998;317:1202-8.

24. Piette JD, Schillinger D, Potter MB, Heisler M. Dimensions of patient-provider communication and diabetes self-care in an ethnically diverse population. J Gen Intern Med 2003;18:624-33.

25. Stewart M. Effective physician-patient communication and health outcomes: a review. Can Med Assoc J 1995;152:1423-33. 